and sutured into the defect of the carina and the right airway (Figure 1, B). After completion of the reconstruction, the endotracheal tube was repositioned in the trachea. The airway and the mediastinum were reinforced by an intrathoracically transposed pedicled latissimus dorsi flap. At the end of the procedure, the patient was extubated. The postoperative course was uneventful. A repeated bronchoscopy revealed morphologic and functional integrity of the airway . Postoperative controls by repeated computed tomographic scan and bronchoscopy revealed no local recurrence or distant metastases as late as 30 months after the operation.

\section{Discussion}

The Kergin procedure was first described in 1952 and was originally designed for airway reconstruction after resection of rightsided centrally located tumors involving the right-sided tracheobronchial angle. ${ }^{4} \mathrm{~A}$ bronchial flap of the medial part of the right main stem bronchus was created during right pneumonectomy and was turned upward order to cover the lateral airway defect at the level of the carina. The technique was applied to 11 patients, with no mortality and uneventful healing of the airway in all cases. ${ }^{5}$

We modified this concept and adapted it to a patient with centrally located NSCLC, originating at the inferior part of the left main stem bronchus and extending to the inferior part of the carina and of the contralateral main stem bronchus. In this situation, the pedicled airway flap was created from the tumor-free cranial circumference of the left main stem bronchus during left pneumonectomy. The flap was rotated downward and allowed a satisfactory reconstruction of the carina and of a $6-\mathrm{cm}$ long defect of the medial aspect of the contralateral airway. This modified left-sided Kergin procedure allowed complete resection of centrally located NSCLC of the left main stem bronchus with direct extension into the carina and the contralateral airway, pretreated by radiochemotherapy. The main advantage of this technique is the avoidance of a risky end-to-end anastomosis after lengthy airway resection in the context of a carinal pneumonectomy after induction therapy.

\section{References}

1. Mitchell JD, Mathisen JD, Wright CD, Wain JC, Donhaue DM, Moncure HC, et al. Clinical experience with carinal resection. $J$ Thorac Cardiovasc Surg. 1999;117:39-53

2. Maeda M, Nakamoto K, Tsubota N, Okada T, Katsura H. Operative approaches for left-sided carinoplasty. Ann Thorac Surg. 1993;56: 441-6.

3. Muehrcke DD, Grillo HC, Mathisen DJ. Reconstructive airway operation after irradiation. Ann Thorac Surg. 1995;59:14-8.

4. Kergin FG. Carcinoma of the trachea. J Thorac Surg. 1952;23:164-8.

5. Gozzetti G, Mastrorilli M, Bragaglia RB, D'Abruzzo GC, Romualdi A, Villani S, et al. The "Kergin pneumonectomy." World J Surg. 1990;14: 624-7.

\title{
Thoracoscopic operation with local and epidural anesthesia in the treatment of pneumothorax after lung transplantation
}

Seiichiro Sugimoto, MD, Hiroshi Date, MD, Ryujiro Sugimoto, MD, Megumi Okazaki, RN, Motoi Aoe, MD, Yoshifumi Sano, MD, and Nobuyoshi Shimizu, MD, Okayama, Japan

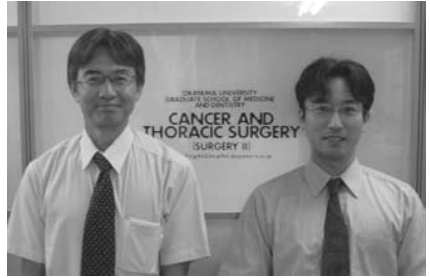

Drs H. Date (left) and S. Sugimoto (right)
$\mathrm{I}$ ntractable pneumothorax in the native or in the transplanted lung may occur after lung transplantation, and successful thoracoscopic repair with general anesthesia has been reported. ${ }^{1}$ For recipients after lung transplantation, however, the risks of general anesthesia itself cannot be negligible, espe-

From the Department of Cancer and Thoracic Surgery, Okayama University Graduate School of Medicine and Dentistry, Okayama, Japan.

Received for publication May 17, 2005; accepted for publication June 30, 2005.

Address for reprints: Hiroshi Date, MD, Department of Cancer and Thoracic Surgery (Surgery II), Okayama University Graduate School of Medicine and Dentistry, 2-5-1 Shikata-Cho, Okayama 700-8558, Japan (E-mail: hdate@nigeka2.hospital.okayama-u.ac.jp).

J Thorac Cardiovasc Surg 2005;130:1219-20

$0022-5223 / \$ 30.00$

Copyright $\odot 2005$ by The American Association for Thoracic Surgery

doi:10.1016/j.jtcvs.2005.06.019 cially during the early postoperative period. We report 2 cases of intractable pneumothorax after lung transplantation successfully treated by thoracoscopic operation with local and epidural anesthesia.

\section{Clinical Summaries}

PATIENT 1. A 47-year-old man with a history of multiple episodes of bilateral pneumothorax underwent right single-lung transplantation for interstitial pneumonia associated with rheumatoid arthritis. Soon after extubation on postoperative day (POD) 9, a significant ulcerative stricture developed in the right main bronchus and was treated with repeated bronchoscopic débridements. On POD 27, the patient had a pneumothorax develop in the native lung. The initial treatment consisted of chest tube drainage. Pleurography was performed through the chest tube, and a major air leak site was found in the left lower lobe. On POD 34, the patient underwent thoracoscopic operation with local and epidural anesthesia. A thoracic epidural catheter was placed immediately before the operation. Ropivacaine $0.2 \%(5-7 \mathrm{~mL})$ was injected into the 
epidural space at induction and added as needed during the operation for analgesia. The patient maintained spontaneous breathing during the subsequent procedure, and oxygen was administered by facial mask as needed. He was then positioned in a right lateral decubitus position. After additional local anesthesia with $1 \%$ lidocaine, a thoracoscope was inserted through the seventh intercostal space at the midaxillary line. The source of the air leak was found to be a ruptured bulla in the left lower lobe. Significant pleural adhesion was seen, and we avoided unnecessary dissection that might create additional air leaks. Two additional ports were inserted carefully to avoid injuring the half-deflated lung. Aerosolized fibrin glue was injected around the hole of the leaking bulla. The bulla was then covered with a piece of polyglycolic acid sheet. We sprayed the sheet with aerosolized fibrin glue and obtained a complete air sealing. The postoperative course was uneventful, and the patient was discharged from the hospital 57 days after singlelung transplantation. Although he required a Dumont stent placement for the anastomotic stricture in the right main bronchus at 4 postoperative months, no pneumothorax has recurred at a follow-up of 40 months.

PATIENT 2. A 37-year-old woman underwent bilateral livingdonor lobar lung transplantation with her elder sister's right lower lobe and her younger sister's left lower lobe for bronchiectasis associated with panbronchiolitis. The total forced vital capacity of the two grafts was estimated to be $53.9 \%$ of the recipient's predicted forced vital capacity. ${ }^{2}$ The postoperative course was complicated by two episodes of severe acute rejection in the right graft and prolonged mechanical ventilation for 25 days. She had a left hydropneumothorax develop and required chest tube drainage. Significant dead space remained, with persistent air leak (Figure 1). The patient underwent thoracoscopic operation with local and epidural anesthesia on POD 51 in the same manner as did patient 1. Her postoperative course was uneventful, and no pneumothorax has recurred at a follow-up of 23 months.

\section{Discussion}

After single-lung transplantation, the contralateral native lung may be the source of early and late pneumothorax related to the progression of the underlying disease in patients with emphysema, pulmonary fibrosis, and lymphangioleiomyomatosis. ${ }^{1}$ Bronchial stenosis in the transplanted lung may lead to preferential ventilation to the native lung, rendering it more susceptible to pneumothorax. ${ }^{3}$ After living-donor lobar lung transplantation, a pleural space problem may increase the risk of pneumothorax, because a limited amount of lung tissue is transplanted. Prolonged mechanical ventilation may favor the onset of pneumothorax. ${ }^{4}$

Successful thoracoscopic repair with general anesthesia has been reported for posttransplantation pneumothorax. However, we

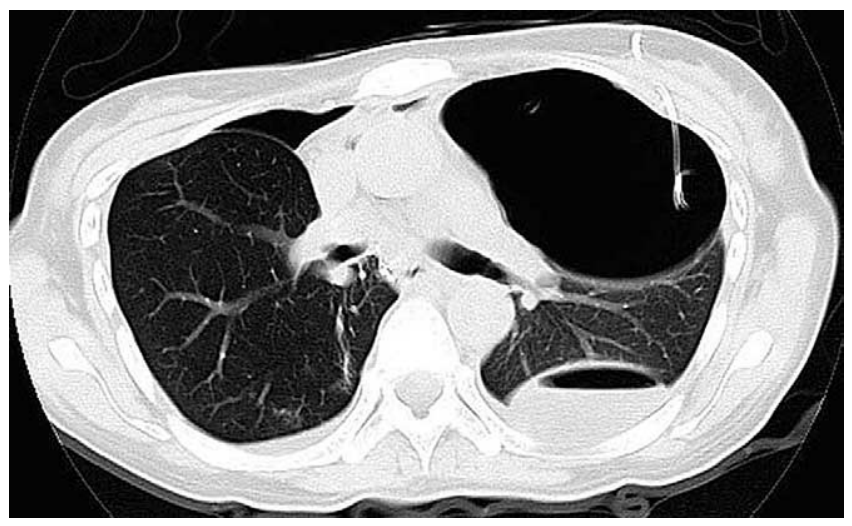

Figure 1. Left hydropneumothorax after bilateral living-donor lobar lung transplantation (patient 2).

thought that it would be difficult to maintain single-lung ventilation in these 2 cases because of bronchial stenosis in patient 1 and a small graft (one lobe) in patient 2.

With local and epidural anesthesia, pain and cough were controllable. Patients maintained spontaneous breathing, with stable blood pressure and arterial blood gas values. The half-deflated lung provided a satisfactory view for the thoracoscopic operation. We simply covered the leaking area with a piece of polyglycolic acid sheet and sprayed the sheet with aerosolized fibrin glue, as described previously. ${ }^{5}$ This method does not require pleural dissection and can shorten the operative time. We believe that thoracoscopic operation in the treatment of pneumothorax with local and epidural anesthesia is useful for lung transplantation recipients with immunosuppression and malnutrition.

\section{References}

1. Venuta F, Boehler A, Rendina EA, De Giacomo T, Speich R, Schmid $\mathrm{R}$, et al. Complications in the native lung after single lung transplantation. Eur J Cardiothorac Surg. 1999;16:54-8.

2. Date H, Aoe M, Nagahiro I, Sano Y, Andou A, Matsubara H, et al. Living-donor lobar lung transplantation for various lung diseases. J Thorac Cardiovasc Surg. 2003;126:476-81.

3. Chhajed PN, Malouf MA, Tamm M, Hopkins PM, Plit M, Glanville AR. Resolution of native lung pneumothorax by insertion of a nitinol stent for bronchostenosis in the transplanted lung. Respirology. 2002; 7:377-9.

4. Date H, Aoe M, Sano Y, Nagahiro I, Miyaji K, Goto K, et al. Improved survival after living-donor lobar lung transplantation. J Thorac Cardiovasc Surg. 2004;128:933-40.

5. Mukaida T, Andou A, Date H, Aoe M, Shimizu N. Thoracoscopic operation for secondary pneumothorax under local and epidural anesthesia in high-risk patients. Ann Thorac Surg. 1998;65:924-6. 